\title{
Ambient air pollution: a cause of COPD?
}

\author{
Tamara Schikowski ${ }^{1,2}$, Inga C. Mills ${ }^{3}$, H. Ross Anderson 4,5 , Aaron Cohen ${ }^{6}$, \\ Anna Hansell 7 , Francine Kauffmann ${ }^{8,9}$, Ursula Krämer ${ }^{10}$, Alessandro Marcon ${ }^{11}$, \\ Laura Perez ${ }^{1,2}$, Jordi Sunyer ${ }^{12,13}$, Nicole Probst-Hensch ${ }^{1,2}$ and Nino Künzli ${ }^{1,2}$
}

\author{
Affiliations: \\ ${ }^{1}$ Swiss Tropical and Public Health Institute, Basel, and \\ ${ }^{2}$ University of Basel, Basel, Switzerland. \\ ${ }^{3}$ Health Protection Agency (HPA) Centre for Radiation, Chemical and Environmental Hazards, Chilton, \\ ${ }^{4}$ Medical Research Council (MRC)-HPA Centre for Environment and Health, St George's, University of London, \\ London, \\ ${ }^{5}$ MRC-HPA Centre for Environment and Health, King's College London, London, and \\ ${ }^{7}$ MRC-HPA Centre for Environment and Health, Imperial College London, London, UK. \\ ${ }^{6}$ Health Effects Institute, Boston, MA, USA. \\ ${ }^{8}$ Inserm, CESP Centre for research in Epidemiology and Population Health, U1018, Respiratory and \\ Environmental Epidemiology Team, Villejuif, and \\ ${ }^{9}$ Université Paris Sud 11, UMRS 1018, Villejuif, France. \\ ${ }^{10}$ IUF-Leibniz Research Institute for Environmental Medicine, Düsseldorf, Germany. \\ ${ }^{11}$ Unit of Epidemiology and Medical Statistics, Dept of Public Health and Community Medicine, University of \\ Verona, Verona, Italy. \\ ${ }^{12}$ Centre for Research in Environmental Epidemiology, Barcelona, and \\ ${ }^{13}$ Universitat Pompeu Fabra, Barcelona, Spain.
}

Correspondence: N. Künzli, Swiss Tropical and Public Health Institute, Socinstrasse 57, 4002 Basel, Switzerland. E-mail: nino.kuenzliqunibas.ch

ABSTRACT The role of ambient air pollution in the development of chronic obstructive pulmonary disease (COPD) is considered to be uncertain. We review the evidence in the light of recent studies.

Eight morbidity and six mortality studies were identified. These were heterogeneous in design, characterisation of exposure to air pollution and methods of outcome definition. Six morbidity studies with objectively defined COPD (forced expiratory volume in $1 \mathrm{~s} /$ forced vital capacity ratio) were cross-sectional analyses. One longitudinal study defined incidence of COPD as the first hospitalisation due to COPD. However, neither mortality nor hospitalisation studies can unambiguously distinguish acute from longterm effects on the development of the underlying pathophysiological changes.

Most studies were based on within-community exposure contrasts, which mainly assess traffic-related air pollution. Overall, evidence of chronic effects of air pollution on the prevalence and incidence of COPD among adults was suggestive but not conclusive, despite plausible biological mechanisms and good evidence that air pollution affects lung development in childhood and triggers exacerbations in COPD patients. To fully integrate this evidence in the assessment, the life-time course of COPD should be better defined. Larger studies with longer follow-up periods, specific definitions of COPD phenotypes, and more refined and source-specific exposure assessments are needed.

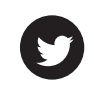

@ERSpublications

Evidence of chronic effects of air pollution on the prevalence and incidence of COPD is suggestive but not conclusive http://ow.ly/pCfjy

\section{Received: June 282012 | Accepted after revision: Feb 242013 | First published online: March 072013}

Support statement: The research leading to this paper has received funding from the European Community's Seventh Framework Programs ESCAPE (FP7-ENV-2007-2011; grant agreement number 211 250), TRANSPHORM (FP7-ENV2009-2011; grant agreement number 243 406), the APHEKOM project (European Commission's Programme on Community Action in the Field of Public Health; Grant Agreement No. 2007105 (LP)), and the Swiss National Science Foundation (TS) (grant \# 324730_133148).

Conflict of interest: None declared.

Copyright @ERS 2014 


\section{Introduction}

In contrast to many other risks, exposure to outdoor air pollution occurs during the entire lifespan. Exposure is usually inevitable and involuntary, and its adverse health effects are well established for a range of outcomes. As in the case of other chronic diseases (e.g. cardiovascular diseases [1]), it is important to distinguish two features of chronic obstructive pulmonary disease (COPD) in the assessment of evidence related to air pollution, namely the long-term development of the chronic obstructive pathology and the superimposed acute exacerbations [2]. In air pollution research, most studies have focused on the role of air pollution in triggering symptoms and exacerbations, i.e. the short-term (acute or subacute) effects of air pollution [3]. As reviewed by SUNYER [4], evidence for a role of air pollution in the acute exacerbation of COPD has been accepted for many years, and more recent studies confirm this conclusion $[3,5]$. The role of air pollution in the long-term development of the pathophysiological changes that characterise COPD are far less clear [6-8]. COPD is presently the fourth leading cause of death, and it is predicted to become the third leading cause by 2030 [9], making this disease one of the major health challenges in the future [2]. In addition, COPD is a risk factor for the development of lung cancer, itself a leading cause of death globally [9]. While smoking is an important risk factor for COPD, it is now agreed that the disease can also have other aetiologies [8].

The reviews of the American Thoracic Society (ATS) [8], up to May 2008, and a special report from the Health Effects Institute (HEI) [10], up to October 2008, have both addressed the role of ambient air pollution in the development of COPD, i.e. the long-term effects. In the ATS review, which focused on the causes of COPD other than active smoking, the conclusion was that there is limited/suggestive evidence for a role of ambient air pollution. The HEI report focused exclusively on traffic-related near-road exposures. It concluded that there are inconsistencies in the existing data and that there is insufficient evidence of an association between local traffic-related pollution and COPD. Since both reviews have been published, a number of new publications have emerged [11-16]. In the light of these, the objective of this review is to reassess the epidemiological evidence for a role of long-term exposure to the complex mixture of outdoor air pollution in the development of objectively defined COPD.

We do not review the studies on acute effects of air pollution on COPD. However, the implications of these effects in the assessment of an aetiological link between air pollution exposure and the development of COPD will be addressed in the Discussion section. We also do not review the established association between indoor exposure to biomass combustion and airway obstruction $[8,17]$. The type, concentration, toxicity and pattern of exposure of pollutants varies widely between indoor and urban ambient outdoor pollution, which makes the generalisation from the health effects of indoor biomass combustion to those of urban or traffic related air pollution rather uncertain [18].

\section{Methods}

\section{Search strategy}

The Medline (PubMed), EMBASE and ISI Web of Knowledge databases were used to identify studies for the literature review, published (including "online first" articles) up to July 2, 2012. The heterogeneous nature of the COPD phenotype definitions and of the mixture of air pollutants required a broad search approach. Keywords included in the search were "air pollution", "PM", "particulate matter", "NO2", "nitrogen dioxide", "O3", "ozone" and "traffic", as well as "COPD", "chronic obstructive pulmonary disease", "obstructive lung disease" and "emphysema". We selected the relevant articles manually by reviewing titles, abstracts and reference lists. The search was limited to articles written in the English language, and studies conducted in humans and adults. Next, several groups of studies were excluded due to their limited ability to contribute to the appraisal of the main question (see later). Potential articles were retrieved and, in a hand search, the referent list of the included articles was checked to identify additional papers. To identify articles relevant to the current analysis, the following sifting criteria were applied: removing duplicates; exclusion of articles that did not address the research question (see later) or did not contain original data; and limiting the search to the English language.

\section{Inclusion and exclusion criteria}

Only original research, fully published in the peer-reviewed literature, was considered from cross-sectional, cohort and case-control studies. Details on how COPD and air pollution were defined had to be provided. The diagnosis of COPD had to be based on objective measures (namely spirometry) or on International Classification of Diseases codes in the hospital discharge or the death record. There are various ways to objectively define COPD [19]. Tables 1 and 2 provide the definitions used in the air pollution studies considered in this review. We also opted for the inclusion of cohort studies with "mortality due to COPD" (or survival) as the outcome where long-term exposure to air pollution was estimated (table 2). However, one may question the use of these studies in the assessment of effects of long-term exposure on COPD 


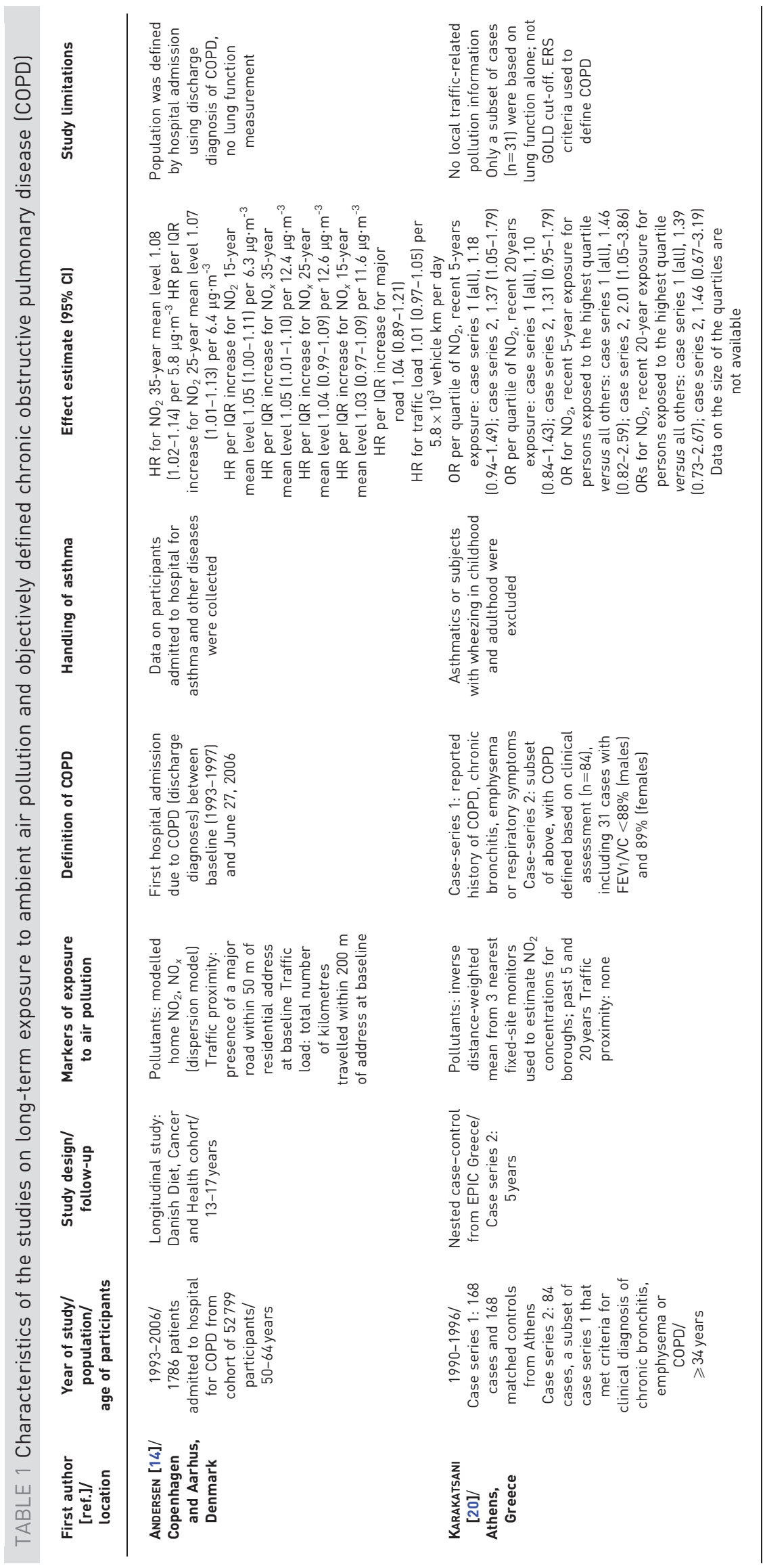




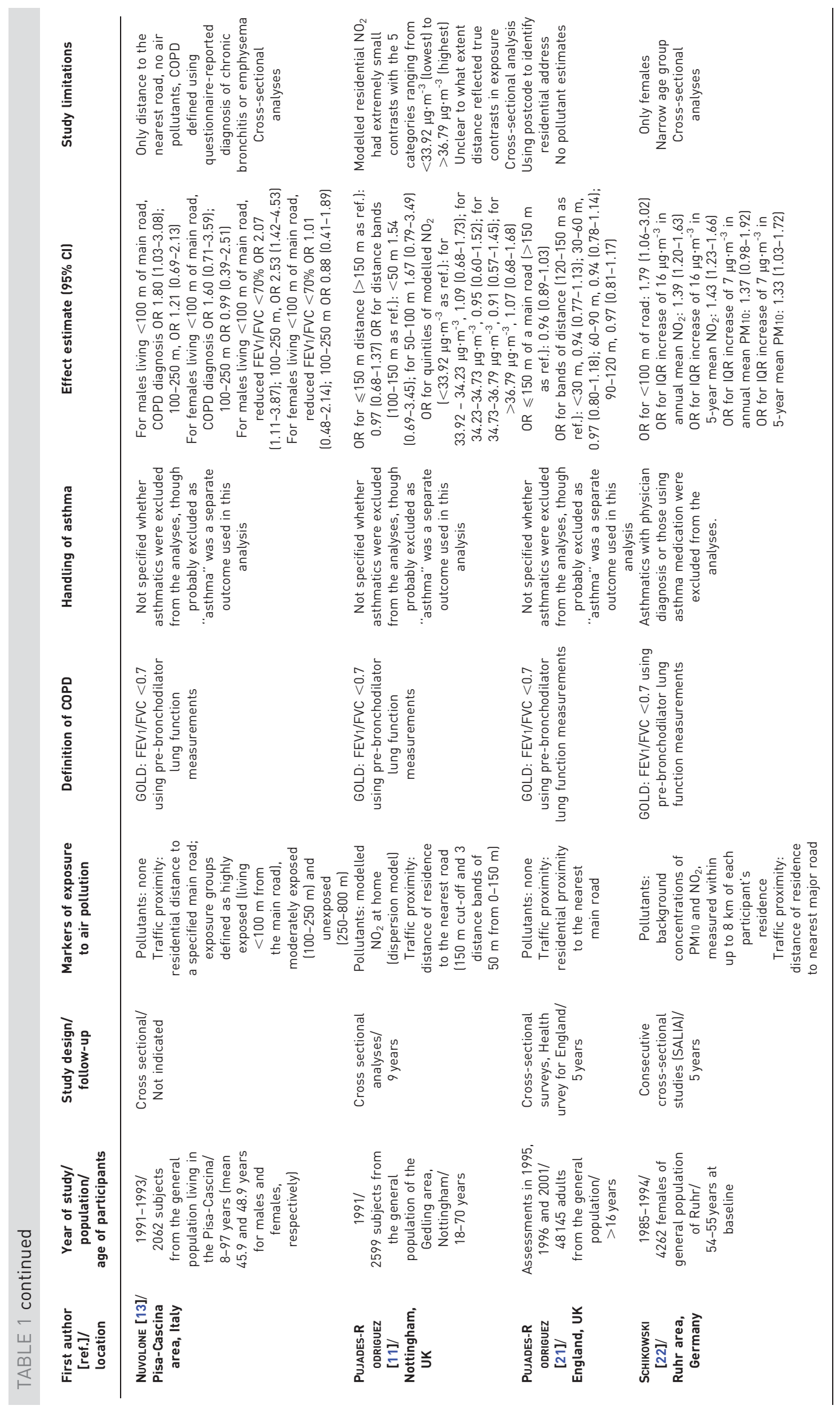




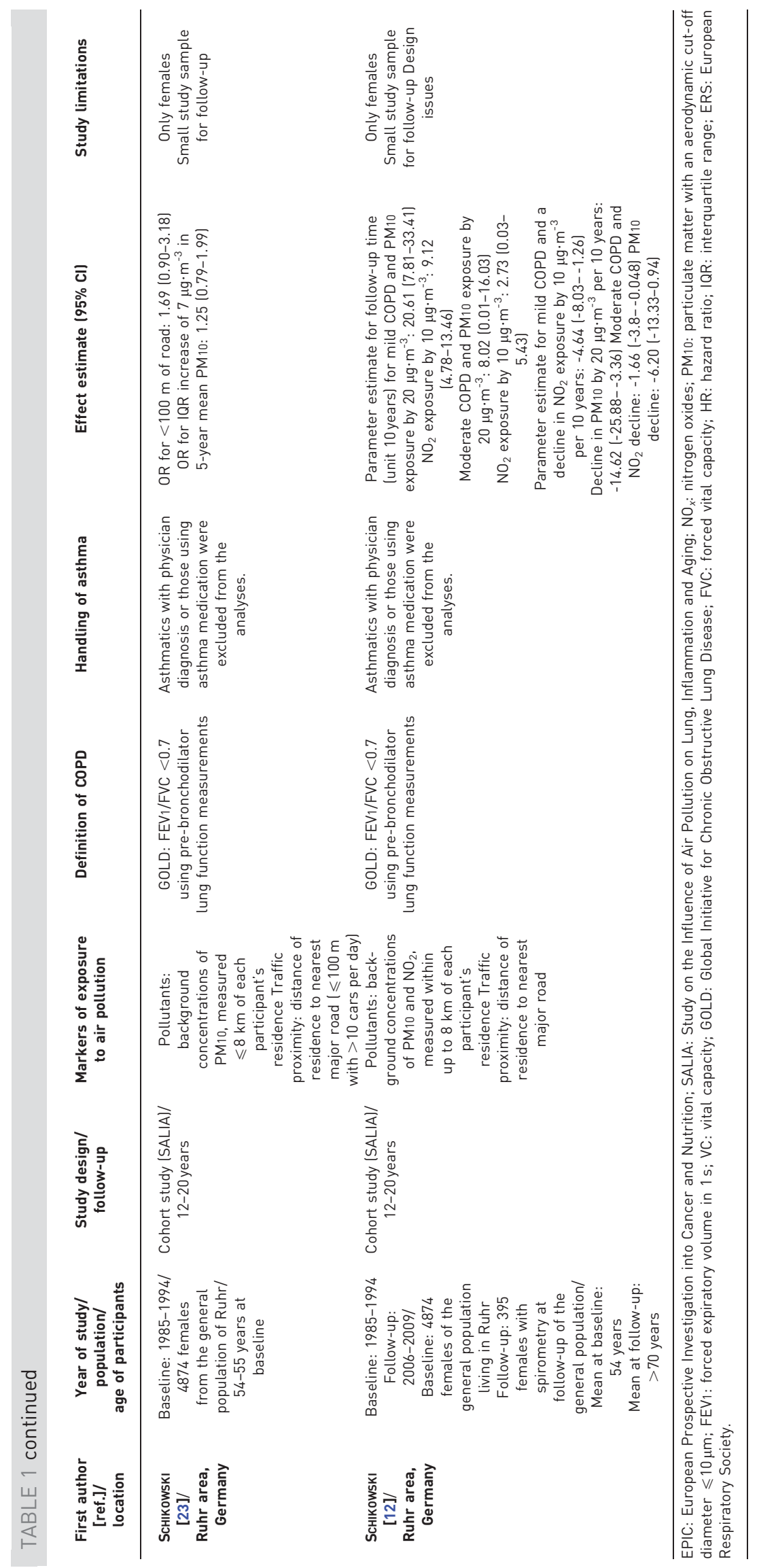


TABLE 2 Characteristics of the studies on long-term exposure to ambient air pollution and survival among patients with chronic obstructive pulmonary disease (COPD) $[15,24]$ or COPD mortality in general cohorts

\begin{tabular}{|c|c|c|c|c|c|c|}
\hline $\begin{array}{l}\text { First author } \\
\text { [ref.]/ } \\
\text { location }\end{array}$ & $\begin{array}{l}\text { Year of study/ } \\
\text { population/ } \\
\text { age at observation }\end{array}$ & $\begin{array}{l}\text { Study design/ } \\
\text { follow-up }\end{array}$ & $\begin{array}{l}\text { Markers of exposure to } \\
\text { air pollution }\end{array}$ & $\begin{array}{l}\text { Definition of COPD } \\
\text { outcome }\end{array}$ & Effect estimate $(95 \% \mathrm{Cl})$ & Study limitation \\
\hline $\begin{array}{l}\text { FINKELSTEIN } \\
\text { [24]/ } \\
\text { Hamilton, } \\
\text { Canada }\end{array}$ & $\begin{array}{c}1985 \text { and } 1999 / \\
5228 \text { patients referred to } \\
\text { pulmonary laboratory }\end{array}$ & $\begin{array}{l}\text { Cohort/ } \\
9 \text { years }\end{array}$ & $\begin{array}{l}\text { Pollutants: none Traffic } \\
\text { proximity: distance to } \\
\text { nearest major road }\end{array}$ & $\begin{array}{l}\text { ICD-9 codes for COPD } \\
\text { mortality; measures } \\
\text { of FEV1 and FVC }\end{array}$ & $\begin{array}{l}\text { Rate of advancement period } \\
\text { for living close to a major } \\
\text { road: } 3.4(0.8-6.0)\end{array}$ & $\begin{array}{c}\text { No direct pollution measurements, } \\
\text { only GIS data was used to assign } \\
\text { air pollution exposure }\end{array}$ \\
\hline $\begin{array}{l}\text { LEPEULE [25]/ } \\
\text { USA }\end{array}$ & $\begin{array}{l}\text { Baseline: } 1974-1977 \\
\text { Last follow-up: } 2009 / \\
8096 \text { subjects from the } \\
\text { Harvard Six Cities study }\end{array}$ & $\begin{array}{l}\text { Cohort/ } \\
20 \text { years } \\
\text { [death from } \\
\text { 1979-2009) }\end{array}$ & $\begin{array}{l}\text { Pollutants: local } \\
\text { centrally measured } \\
\text { levels of PM10 and } \\
\text { PM2.5 } \\
\text { Traffic proximity: none }\end{array}$ & $\begin{array}{l}\text { ICD-10 codes for } \\
\text { COPD mortality; all } \\
\text { patients underwent } \\
\text { spirometry, measures } \\
\text { of FEV1 and FVC }\end{array}$ & $\begin{array}{c}\text { Adjusted RR for } 10 \mu \mathrm{g} \cdot \mathrm{m}^{-3} \\
\text { increase in PM2.5: never- } \\
\text { smoker, } 0.85(0.36-2.02) \text {; } \\
\text { former smoker, } 1.64 \\
\text { (0.92-2.93); current smoker, } \\
\text { 1.10 (0.74-1.62) }\end{array}$ & $\begin{array}{l}\text { Only adjustment for baseline } \\
\text { factors, PM2.5 was not measured } \\
\text { in same location throughout the } \\
\text { study period }\end{array}$ \\
\hline $\begin{array}{l}\text { NAESs [26]/ } \\
\text { Oslo, } \\
\text { Norway }\end{array}$ & $\begin{array}{c}1992-1998 / \\
143842 \text { subjects from the } \\
\text { general population of Oslo/ } \\
51-70 \text { and } 71-90 \text { years }\end{array}$ & $\begin{array}{l}\text { Cohort/ } \\
14 \text { years }\end{array}$ & $\begin{array}{l}\text { Pollutants: dispersion } \\
\text { model of } \mathrm{NO}_{2}, \mathrm{PM} 10 \text { and } \\
\mathrm{PM} 2.5 \text { to calculate } \\
\text { individual daily average } \\
\text { exposure estimates } \\
\text { Traffic proximity: None }\end{array}$ & $\begin{array}{l}\text { ICD-9 codes } 490-496 \\
\text { (COPD) and ICD-10 } \\
\text { codes I00-I119 for } \\
\text { COPD mortality } \\
\text { Limitation: no lung } \\
\text { function measures }\end{array}$ & $\begin{array}{c}\text { Age group } 51-70 \text { years: HR } \\
\text { for highest quartile } \\
>42 \mu \mathrm{g} \cdot \mathrm{m}^{-3} \mathrm{NO}_{2}: 1.21 \\
(1.05-1.39) ; \mathrm{PM} 10: 1.29 \\
(1.12-1.48) ; \mathrm{PM} 2.5: 1.27 \\
(1.11-1.47)\end{array}$ & $\begin{array}{l}\text { Study based on registry data } \\
\text { only, no information about } \\
\text { confounders such as smoking }\end{array}$ \\
\hline $\begin{array}{l}\text { PoPE [27]/ } \\
\text { USA }\end{array}$ & $\begin{array}{l}1979-1983 \text { and } 1999-2000, \\
16 \text {-year follow-up/ } \\
500000 \text { subjects from the } \\
\text { general population }\end{array}$ & Cohort & $\begin{array}{l}\text { Pollutants: background } \\
\text { measures of PM2.5 } \\
\text { Traffic proximity: none }\end{array}$ & $\begin{array}{l}\text { ICD-10 codes I00-I119 } \\
\text { for COPD mortality } \\
\text { Limitation: no lung } \\
\text { function measures }\end{array}$ & $\begin{array}{l}\text { RR for increase of } 10 \mu \mathrm{g} \cdot \mathrm{m}^{-3} \\
\text { PM2.5: } 0.84(0.77-0.93)\end{array}$ & $\begin{array}{l}\text { No lung function, coding from } \\
\text { death records only }\end{array}$ \\
\hline $\begin{array}{l}\text { YORIFUJI } \\
\text { [16]/ } \\
\text { Shizuoka, } \\
\text { Japan }\end{array}$ & $\begin{array}{l}1999-2006 / \\
14001 \text { subjects from the } \\
\text { general population }\end{array}$ & $\begin{array}{l}\text { Cohort/ } \\
7 \text { years }\end{array}$ & $\begin{array}{l}\text { Pollutants: } \mathrm{NO}_{2} \\
\text { modelled (LUR models) } \\
\text { Traffic proximity: none } \\
\text { Pollutants: daily } \\
\text { monitoring measures to } \\
\text { create yearly averages } \\
\text { of PM10 } \\
\text { Traffic proximity: none }\end{array}$ & $\begin{array}{l}\text { ICD-10 codes for } \\
\text { COPD mortality } \\
\text { Mortality (case } \\
\text { fatality) } \\
\text { Limitation: no lung } \\
\text { function measures }\end{array}$ & $\begin{array}{c}\text { Adjusted } \mathrm{HR} \text { for } 10 \mu \mathrm{g} \cdot \mathrm{m}^{-3} \\
\text { increase in } \mathrm{NO}_{2}: 1.11 \\
(0.78-1.56) ; \mathrm{PM} 10 \text { in older } \\
\text { subjects: } 1.14(1.12-1.16) ; \\
\text { younger subjects: } 1.11 \\
(1.08-1.13)\end{array}$ & $\begin{array}{c}\text { No additional information about } \\
\text { confounding available, study } \\
\text { Population was defined by COPD } \\
\text { admission, but no information on } \\
\text { smoking or other confounders } \\
\text { available }\end{array}$ \\
\hline $\begin{array}{l}\text { ZANOBETTI } \\
\text { [15]/ } \\
\text { USA }\end{array}$ & $\begin{array}{c}1985-1999 / \\
1039287 \text { hospital dis- } \\
\text { charges of patients hospi- } \\
\text { talised with COPD (ICD-9 } \\
\text { code } 491 ; 492 ; 494-496 \text { used } \\
\text { to define COPD)/ } \\
\geqslant 65 \text { years }\end{array}$ & $\begin{array}{l}\text { Cohort/ } \\
4 \text { years }\end{array}$ & $\begin{array}{l}\text { Pollutants: daily } \\
\text { monitoring measures to } \\
\text { create yearly averages } \\
\text { of PM10 } \\
\text { Traffic proximity: none }\end{array}$ & $\begin{array}{l}\text { Mortality (case } \\
\text { fatality) } \\
\text { Limitation: no lung } \\
\text { function measures }\end{array}$ & $\begin{array}{c}\mathrm{HR} \text { for } 10 \mu \mathrm{g} \cdot \mathrm{m}^{-3} \text { increase in } \\
\mathrm{PM} 10 \text { in older subjects, } 1.14 \\
(1.12-1.16) ; \text { younger } \\
\text { subjects, } 1.11(1.08-1.13)\end{array}$ & $\begin{array}{c}\text { Population was defined by COPD } \\
\text { admission, but no information on } \\
\text { smoking or other confounders } \\
\text { available }\end{array}$ \\
\hline
\end{tabular}

ICD: International Classification of Diseases; PMx: particular matter with an aerodynamic cut-off diameter of $\leqslant x \mu m$; LUR: land use regression; FEV1: forced expiratory volume in $1 \mathrm{~s}$; FVC: forced vital capacity; RR: relative risk; HR: hazard ratio; GIS: geographic information system.

development. We include them nevertheless as authors claim indeed to assess "long-term effects" although it may be difficult to truly distinguish acute from long-term effects with these studies. The extent to which such mortality studies play a role in helping us understand the question addressed in this review will be addressed in the Discussion.

Quantitative measures of associations, such as odds ratios or relative risks (RRs) and 95\% confidence intervals, or enough data to allow the derivation of these numbers had to be available from the papers.

All eligible articles were systematically described and qualitatively assessed. Studies were excluded for the following three reasons.

\section{Phenotype definition}

Studies which used only questionnaire-based definitions (e.g. chronic symptoms or "doctor-diagnosed COPD" etc.) of COPD were excluded. These definitions lack standardisation and, most importantly, the concepts and terms used both by doctors and patients have changed over time ("chronic bronchitis", "emphysema", "chronic lung disease", etc.). Moreover, symptoms may be a marker of exacerbations or associated with short-term exposure to air pollution, which is not the subject of this review. In addition, we did not include the many studies assessing the association between air pollution and measures of lung function (forced expiratory volume in $1 \mathrm{~s}$ (FEV1), forced vital capacity (FVC) and FEV1/FVC ratio) as the only health outcome, i.e. with no explicit derivation of COPD stages. This is because: 1) these studies have already been reviewed by GÖTSCHI et al [28]; 2) while spirometry is essential for the objective identification of "COPD", the clinical definition of the disease continues to be based on well-defined cut-offs and stages; and 3) published associations between pollution and the level of FEV1 or FEV1/FVC are not easily translated into a measure of COPD prevalence, and the rate of change in lung function (i.e. the main outcome of 
longitudinal lung function studies), which ultimately determines COPD, is not defined. Evidence from air pollution/lung function studies is, therefore, not sufficiently specific or sensitive to address the hypothesis of interest to our review. The lung function studies, reviewed by GöTSCHI et al. [28], provide valuable complementary information to be put in context in the Discussion section of this review.

Acute effects

Studies of various designs have observed correlations between the temporal changes in air quality (acute exposure) and fluctuations of lung function, COPD-related symptoms, hospitalisations and death. The evidence of acute effects is complemented by experimental studies demonstrating, for example, that exposure to ambient particulate matter jeopardises defense mechanisms against viruses or bacteria, a main cause of exacerbations in COPD [2]. This review does not include studies on short-term exposure to air pollution and acute exacerbations (e.g. studies on bronchitis symptoms, hospital admissions or doctor visits). These "acute effect" studies cannot clarify the question of whether frequent exacerbations are a cause of COPD or simply the expression of the underlying chronic pathology. For discussion purposes we include, however, one currently unique longitudinal study with 13 years of follow-up where the new onset of COPD was defined as the first occurrence of a "hospitalisation due to COPD" among a cohort without COPD at baseline [14]. Inferential limitations of this study and of acute effect studies in general will be addressed in the Discussion section.

\section{Ecological comparison}

A few studies compared COPD-related outcomes across only two or three aggregate levels of exposure (usually communities or cities). Such studies have very low power and generally cannot control for confounding factors at the individual level. For example, JIN et al. [29] compared COPD mortality across three districts of Benxi, one of the most polluted cities in China. While mortality patterns followed the gradients in air quality, control for other district specific factors (e.g. working in industry or smoking) was not possible. Such studies are not included in our assessment.

\section{Results}

The flowchart (fig. 1) gives an overview of the results from the screening process. The initial search yielded 689 articles. The manual search through references and journals yielded an extra 3 articles. A total of 26 articles were retained for further evaluation, the remaining 663 articles not addressing the research question were excluded. After a final screen, a further 12 papers were excluded because they did not address the exact research question or did not contain original data. 14 papers were finally included in the analysis, all containing the end-point of interest, namely the incidence or prevalence of COPD or mortality due to COPD.

\section{Air pollution and COPD morbidity}

Table 1 summarises eight articles based on five European studies that used objectively defined COPD as the outcome. All studies defined COPD on the basis of pre-bronchodilator spirometry. The first publication was a Greek case-control study [20]. Apart from the cohort study of ANDERSEN et al. [14], all others were cross-sectional analyses.

KARAKATSANI et al. [20] used background nitrogen dioxide measures to assess the effect of air pollution in COPD cases and controls. They employed a nested case-control approach based on the Greek chapter of the EPIC (European Prospective Investigation into Cancer and Nutrition) cohort. Case series $1(\mathrm{n}=168)$ was based on questionnaire data only, but all were visited by a physician for spirometry and a clinical assessment, which was used to define a subset of 84 subjects (case series 2) fulfilling clinical criteria for diagnosis of chronic bronchitis or emphysema or COPD $(n=31)$ objectively defined as FEV1/vital capacity ratio $<88 \%$ and $<89 \%$ predicted in males and females, respectively. Individually assigned estimates of exposure to traffic-related pollutants showed increased exposure odds, but statistically significant results were observed only in case series 2 for the last 5 years of exposure. Those in the highest exposure quartile had twice the risk of having COPD as compared with those in the bottom quartile (OR 2.01, 95\% CI 1.05-3.68). The study had insufficient power to focus on the 31 objectively defined cases.

The three analyses of the German Study on the Influence of Air Pollution on Lung, Inflammation and Aging (SALIA) [12, 22, 23] specified COPD according to Global Initiative for Chronic Obstructive Lung (GOLD) criteria. The 5-year mean of particulate material with an aerodynamic cut-off diameter $\leqslant 10 \mu \mathrm{m}(\mathrm{PM} 10)$, measured within $8 \mathrm{~km}$ of participants' residences, showed not only significant negative associations with FVC and FEV1 but also a positive association with the odds of having COPD (GOLD stages 1-4): OR 1.33 (95\% CI 1.03-1.72) for an increase of $7 \mu \mathrm{g} \cdot \mathrm{m}^{-3}$ in annual mean PM10 [21]. SALIA is based on females only and the vast majority were never-smokers. Females living within $100 \mathrm{~m}$ of a busy road also had poorer lung 


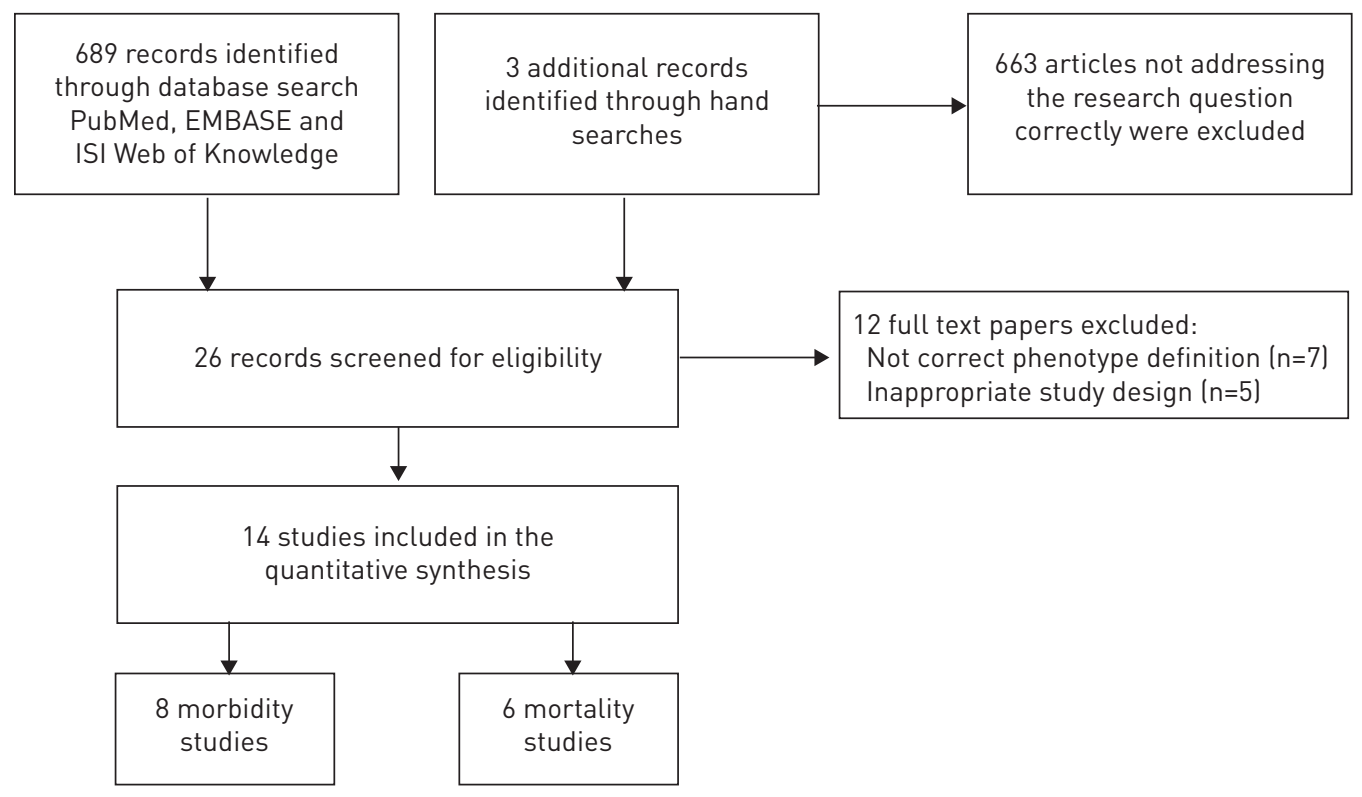

FIGURE 1 Flow diagram.

function and an increased risk of COPD (1.79, 95\% CI 1.06-3.02) [12]. In the second paper from SCHIKOWski et al. [22], the same exposure estimates were used in a subsample of the study population. The risk of developing COPD was increased, although not significantly, in this subsample with OR 1.25 (95\% CI 0.79-1.99) for PM10; the same was true for the distance to the nearest road (OR 1.69, 95\% CI 0.90-3.18). The extended analysis of the same cohort showed that the risk of developing COPD decreased with decline in $\mathrm{PM}_{10}$ and $\mathrm{NO}_{2}$ [12].

The first paper by PuJADES-Rodriguez et al. [21] is based on 41479 adult participants of the 1995, 1996 and 2001 Health Survey for England. Spirometry to define COPD (FEV1/FVC <70\%) was available in 32912 adults. The only metric to describe exposure to air pollution was distance to the nearest main road, dichotomised at a cut-off of $150 \mathrm{~m}$ and in $30-\mathrm{m}$ bands from 0 to $150 \mathrm{~m}$. COPD prevalence was not associated with distance.

The second study of PUjAdes-Rodriguez et al. [11] used data from adults recruited from the Nottingham area (UK) in 1991 to study diet and chronic lung diseases. Spirometric data defining COPD (i.e. FEV1/FVC $<70 \%$ ) were available in 2599 subjects. Distance to a main road (150 m cut-off and three bands of $50 \mathrm{~m}$ from 0 to $150 \mathrm{~m}$ ) and modelled nitrogen dioxide concentrations were assigned to each residence. Crosssectional analyses of the baseline data showed no association between those exposures and COPD prevalence. Neither FEV1 at baseline nor the change in FEV1 (1991-2000) were associated with exposure. COPD incidence was not analysed.

The Italian study by Nuvolone et al. [13] based on a population sample $(\mathrm{n}=2062)$ from the Pisa region used only distance to major roads as the marker of exposure, namely living within $100 \mathrm{~m}, 100-250 \mathrm{~m}$ and 250-800 m. In males, the odds of having GOLD-defined COPD was associated with living within $100 \mathrm{~m}$ of a major road (OR 2.07, 95\% CI 1.11-3.87). In females, proximity was not associated with COPD. Estimates were adjusted for active and passive smoking as well as other relevant covariates.

The Danish study by ANDERSEN et al. [14] used hospital admission data from 52799 patients of the Danish Diet, Cancer and Health cohort. The first hospitalisation due to COPD (discharge diagnosis) occurring between baseline and follow-up was used to define "COPD incidence". Exposure to air pollution was defined as individually modelled 35- and 25-year average home outdoor nitrogen dioxide and nitrogen oxides $\left(\mathrm{NO}_{x}\right)$ concentrations as well as the presence of a major road within $50 \mathrm{~m}$, and traffic load (i.e. total distance travelled) within $200 \mathrm{~m}$ of the residential address at baseline. The hazard ratio (HR) for a 25-year mean of nitrogen dioxide was 1.07 (95\% CI 1.01-1.13) per $6.4 \mu \mathrm{g} \cdot \mathrm{m}^{-3}$ (the interquartile range). Traffic markers were not significantly associated with COPD hospital admission.

\section{Air pollution and COPD mortality}

Table 2 lists the six articles providing results on the association between air pollution and COPD mortality, which was defined using International Classification of Diseases (ICD)-9 or ICD-10 codes. These 
publications used cohort data from Canada, Japan, Norway and the USA. Two studies investigated survival in patients with COPD, whereas the others addressed the impact of air pollution on mortality due to COPD.

\section{Survival in subjects with COPD}

The Canadian study by FinkelsTEIN et al. [24] had spirometry measurements, and clinic-based ICD-9 codes for the definition of chronic pulmonary disease (CPD) (excluding asthma) in this patient-based cohort. Distance to the nearest major road was the only marker of exposure (road buffers of 50 and $100 \mathrm{~m}$ ). The outcome was not incidence of COPD but death among subjects with defined CPD (excluding asthma). A total of 923 deaths occurred during the 9 years of follow-up. Residence within the road buffer was similarly related to higher death rates (due to all natural causes) both in those with CPD and the other subjects, reaching statistical significance only in the total study sample $(1.18,95 \%$ CI $1.02-1.38)$. The effect of road proximity translated into a rate advancement period of 2.5 years (95\% CI $0.2-4.8$ years), i.e. subjects not living in these buffers would need to be 2.5 years older at baseline to experience the same mortality rate as those living along busy roads.

ZANOBETTI et al. [15] used Medicare data (USA) from patients aged $\geqslant 65$ years discharged from hospitals with COPD to construct a cohort of survivors between 1985 and 1999. The authors used 12-month averages of PM2.5 and PM10 to investigate the effects of pollution on mortality in COPD patients. They found significant associations for a $10 \mu \mathrm{g} \cdot \mathrm{m}^{-3}$ increase in PM10 and mortality (HR 1.11, 95\% CI 1.06-1.15).

\section{COPD mortality in general cohorts}

The 16-year follow-up of the American Cancer Society (ACS) study [27] is based on over half a million people. A $10 \mu \mathrm{g} \cdot \mathrm{m}^{-3}$ increase in fine particulate matter (PM2.5) was associated with an increased risk of allcause mortality. However, mortality due to COPD and allied conditions was negatively associated with PM2.5 concentrations (RR 0.84, 95\% CI 0.77-0.93), especially in current and former smokers, but the association was not significant in never smokers (0.96, 95\% CI 0.73-1.24). Deaths due to "pneumonia and influenza" were in contrast positively associated with PM2.5, reaching statistical significance among neversmokers $\left(1.20,95 \%\right.$ CI $1.02-1.41$ per $\left.10 \mu \mathrm{g} \cdot \mathrm{m}^{-3}\right)$.

The Norwegian cohort followed mortality patterns among 143842 subjects from the general population over 14 years. The authors used local nitrogen dioxide, PM10 and PM2.5 measures to assign exposure. COPD mortality was significantly associated with all pollutants. Subjects exposed to concentrations above the highest quartile of PM10 (i.e. $>19 \mu \mathrm{g} \cdot \mathrm{m}^{-3}$ ) had a HR of 1.29 (95\% CI 1.12-1.48) as compared to those in the lowest quartile $\left(<14 \mu \mathrm{g} \cdot \mathrm{m}^{-3}\right)$. A similarly high association could be observed for PM2.5 (HR 1.27, 95\% CI 1.11-1.47) and nitrogen dioxide (HR 1.29, 95\% CI 1.05-1.39) [26].

A Japanese study with a 7-year follow-up of a random population sample from all 74 municipalities of Shizuoka $(n=14001)$ showed a nonsignificant HR for COPD mortality associated with a $10 \mu \mathrm{g} \cdot \mathrm{m}^{-3}$ increase in nitrogen dioxide (HR 1.11, 95\% CI 0.78-1.56) [16].

In an extended follow-up of the Harvard Six Cities study, using 20 years of survival follow-up of a random sample of adults living in sex cities in the East and Midwest USA, the authors found a positive but not statistically significant risk of death due to COPD. In former smokers, a $10 \mu \mathrm{g} \cdot \mathrm{m}^{-3}$ increase in PM $2.5 \mathrm{was}$ associated with a relative risk of 1.64 (95\% CI 0.92-2.93), in current smokers of 1.10 (95\% CI $0.74-1.62$ ) and in never-smokers of 0.85 (95\% CI 0.36-2.02) [25].

\section{Discussion}

Due to the lack of studies, the role of ambient air pollution in the development of objectively defined COPD was considered uncertain in previous reviews $[4,8,10]$. In fact, only two of the studies listed in table 1 were previously considered. Our review took into account eight studies on COPD morbidity (mostly prevalence) and six cohort studies on COPD related mortality or survival among COPD patients. Overall, results remain inconclusive but require consideration of a range of complex issues. First, we discuss issues related to single studies and heterogeneities in exposure assessment. We will then address challenges faced by research on the aetiology of COPD, namely the limitations of using mortality studies, the difficulties in interpreting studies on short-term exposure and acute outcomes, the link between acute episodes and chronic pathologies, uncertainties in the definition of COPD phenotypes, and a better insight into the life-time course of COPD.

\section{Study-specific issues and exposure assessment}

The cross-sectional analyses from Germany and Italy and the Greek case-control study suggest that subjects exposed to near-road traffic-related air pollution have a higher risk of COPD. In contrast, the crosssectional study from England and the smaller one from Nottingham observed no clear association with residential proximity to busy roads. One origin of inconsistencies may be the lack of information about 
susceptibility factors modifying the adverse effects of air pollution. The studies listed in tables 1 and 2 addressed, if any, only differences between males and females and across categories of smoking with no clear patterns emerging.

The interpretation of the null findings from the Nottingham study for the modelled nitrogen dioxide values raises the question of whether exposure contrasts were sufficiently large in the UK studies. As shown in table 1, the nitrogen dioxide range was extremely narrow, indicating that people share very similar background levels of pollution. Exposure assessment is, in general, a source of complexity in these studies. Different pollutants and sources may play different roles in the development and exacerbation of health effects. For example, current evidence indicates that near-road traffic-related pollutants may cause the onset of asthma in children, whereas the more homogenously distributed, mostly secondary, urban background pollutants are less clearly associated with asthma onset [30,31]. The studies listed in table 1 focused on markers of traffic-related pollution using different and hardly comparable exposure concepts, such as various buffers of proximity or modelled local as well as background $\mathrm{NO}_{x}$ concentrations. This heterogeneity in the exposure assessment hinders the comparative evaluation of the results and the derivation of quantitative estimates across studies.

Differences between cross-sectional studies may, in part, be a result of exposure misclassification resulting from different patterns, so migration and incomplete assessment of confounders may be of some relevance too.

\section{Inherent limitations in using mortality studies to assess aetiological evidence}

The interpretation of the mortality studies listed in table 2 is a challenge. If air pollution triggers or prolongs exacerbations among COPD patients as an acute effect, mortality due to COPD is expected to be higher among those living in more polluted sites, as observed in Norway [26], Japan [16] and (though without statistical significance) in the ACS study from the USA [27]. One would observe such associations in particular in following up cohorts of COPD patients. Indeed, FINKELSTEIN et al. [24] and ZANOBETTI et al. [15] reported significant associations of air quality with survival among COPD patients. One may interpret this finding as a long-term effect of air pollution on the progression of the underlying pathologies that result in COPD. Although not directly observed in these cohort studies, one may conjecture that progression to premature mortality reflects enhanced disease development in the pre-clinical and clinical stages of COPD development. However, one may interpret the results as well as a consequence of acute or subacute effects of air pollution on patients with COPD, resulting in shortening life time. Thus, whether and to what extent COPD was caused or enhanced by long-term exposure to air pollution cannot be unambiguously inferred from these mortality studies.

In the case of COPD, cause-specific mortality studies are challenged by a further and possibly influential problem, namely the low sensitivity of death certificates for this disease [32]. As reported, for example, for the UK, death certificate analyses using underlying cause of death heavily underreport the contribution of obstructive lung disease to mortality [33]. COPD is loosely defined, underdiagnosed, and substantially linked with comorbidities including cardiovascular diseases, diabetes and lung cancer [2], and these may be preferentially reported on death certificates. Discrepancies in coding and diagnostic labelling may also explain at least part of the large differences in COPD-related deaths observed across countries [34]. Moreover, practitioners are more likely to use the diagnostic label "COPD" in smokers and males, thus further affecting sensitivity of death certificates among never-smokers, a group of particular interest for our research question.

In fact, the negative finding of the ACS study by POPE et al. [27] (table 2) provides an example of the challenges faced as a result of the likely limited validity of COPD on death certificates and the inability to clearly distinguish acute from chronic effects. While associations between air pollution and reduced life expectancy were strong for all natural deaths and for cardiovascular death, this was not the case for COPD as defined on the death certificates. However, associations between "long-term exposure" and "pneumonia or influenza" as the cause of death were strong and significant. Pneumonia is, by definition, an acute disease of limited duration but an important terminal cause of death among those with COPD. Pneumonia is a key feature of COPD exacerbations and it may well be that many subjects with pneumonia, enhanced by air pollution, had an underlying COPD which, however, was not acknowledged in the death certificate. The findings of the Harvard Six Cities Study may also indicate diagnostic labelling or underdiagnosis of COPD related to smoking status. The null findings in never-smokers and the positive, although not significant, results reported for current and former smokers may in part be seen as a consequence of differential misclassification of the outcome (table 2).

Mortality studies are of particular use in the estimation of the burden and costs attributable to air pollution. In fact, the 2010 update of the World Health Organization Global Burden of Disease will integrate mortality due to COPD, based on published and unpublished estimates of the association, also using unpublished 
estimates from the ACS study (RR 1.05, 95\% CI 0.95-1.17 for COPD mortality per $10 \mu \mathrm{g} \cdot \mathrm{m}^{-3} \mathrm{PM} 2.5$ ) and the California Teachers Study (RR 1.21, 95\% 0.88-1.68 per $\left.10 \mu \mathrm{g} \cdot \mathrm{m}^{-3} \mathrm{PM} 2.5\right)[35,36]$.

\section{Limitations in using acute outcomes to assess the evidence of long-term effects}

The prospective cohort study from Denmark supports an association between traffic-related air pollution and COPD-related risk [14]. Although one may give the strongest weight of evidence to results from longitudinal studies, the interpretation of this cohort study needs caution. First, the use of hospital discharge diagnosis to define COPD may not necessarily guarantee that the diagnostics included spirometry. Second, and most importantly, the interpretation of the findings as "long-term effects" may be questioned. Elaborate state-of-the-art models of long-term air pollution distribution were used to individually assign exposure to traffic-related pollution to $>50000$ subjects, followed over $>13$ years. The outcome, however, was not the incidence of COPD but rather time to the first hospital admission due to COPD. The data give strong evidence for air pollution playing a role in exacerbations of COPD severe enough to require hospitalisation, confirmed by previous studies [4]. With hospital admission, an acute event, as the primary outcome, the study cannot unambiguously distinguish the role of air pollution in exacerbating COPD (developed due to other causes) from its aetiological contribution to the development of COPD. The use of long-term exposure averages does not resolve this inherent uncertainty. As shown by the same authors in similar analyses on air pollution and asthma hospital admissions in the same Danish cohort, short- and long-term levels of air pollution were highly correlated [14]. The ambiguity in the interpretation of such hospital admission data has been discussed in an accompanying editorial of the asthma analyses [1]. Given that air pollution is an established trigger of both asthma attacks and exacerbations of COPD, related hospital admissions remain an ambiguous outcome to establish the role of air pollution in causing the pathologies that underlie these chronic diseases.

This brings up the more general question of how to interpret the role of acute effects of air pollution (e.g. on pneumonia, bronchitis symptoms or other acute episodes) in the causation of COPD. The continued loss of lung function coupled with chronic bronchitis symptoms, dyspnoea, disability and, ultimately, premature death clinically characterise COPD during later stages. Subjects free of COPD with a history of chronic bronchitis symptoms are more likely to develop COPD later in life [37]. Repeated acute insults contribute, in the long-term, to a more rapid decline of lung function $[38,39]$. Under this aetiological model, exacerbations are not only the expression of COPD but a cause of the development of the disease. Bronchitis symptom episodes are triggered and possibly prolonged by ambient air pollution (acute effects) [6]. Without a more complete understanding of the role of air pollution-related exacerbations in the aetiology of COPD, it remains difficult to establish the role of acute exposures in the development of COPD.

\section{Definition of COPD phenotypes}

The loose definition of the phenotype is an inherent challenge in the assessment of aetiology. COPD is characterised by irreversible airflow limitation, inflammation in the airways, and a range of systemic pathologies and comorbidities. Spirometry is essential for the definition of "COPD" and it provides the basis to describe the severity of COPD. However, although obstructed airways with reduced lung function are a hallmark of the disease, the clinical phenotypes can substantially differ in terms of clinical appearance, morphological characteristics, or temporal course and features, indicating the existence of various phenotypes characterised by airway obstruction. Risk factors, including air pollution, may play different roles among the various phenotypes. In the absence of tools to objectively define those phenotypes, progress in aetiological research may be limited. Related to this, the distinction between the two main obstructive diseases, asthma and COPD, is a further challenge in this research. While some of the studies in table 1 excluded subjects with asthma to increase the specificity of COPD, none of the studies used postbronchodilator spirometry to distinguish COPD from asthma. Moreover, secular changes in early-life conditions, which have increased asthma incidence, may also modify the aetiology of COPD. In fact, both asthma and COPD may comprise a set of subgroups of disease entities, or endotypes (i.e. subtypes defined by distinct pathophysiological mechanisms) [40-42]. The lack of specificity in the definition of such endotypes may result in biased results if air pollution is differently associated with different endotypes.

\section{Life-time course of COPD and lung function}

The natural history of COPD is defined by a progressive decline in lung function (FEV1 and FVC) leading to earlier and/or larger deficits than might be expected in normal aging. A reduction in the postbronchodilator FEV1 and a low FEV1/FVC ratio are the primary markers of COPD. However, the classification of normal and abnormal, the presence or absence of COPD, and the clinical course are subjects of ongoing debate. Most importantly, to what degree subnormal development of lung function during the growth phase (childhood/adolescence) may reflect the earliest pre-clinical phase of COPD is not clear, and the trajectories of lung function over the life span are still poorly understood [43]. While accelerated decline 
of lung function is a main feature of the disease throughout adulthood, not all "accelerated decline" of lung function results in COPD. The associations and causal link of the lung function growth in adolescence, the lung function level during the plateau phase in young adults, and the rate of lung function decline during adulthood with the incidence of COPD in adulthood are not defined. With uncertainties about the natural history of COPD in mind, it is unclear how to link the abundant evidence of a causal association between longterm exposure to air pollution and decelerated lung function growth (childhood) and accelerated lung function decline (adulthood) with the aetiological role of air pollution in the development of COPD [20, 44].

\section{Conclusion and outlook}

We are left with interpreting the aetiological evidence provided by studies listed in table 1 (except that of ANDERSEN et al. [14]). Lessons learned are summarised in table 3. The data are suggestive of a role for ambient air pollution in the aetiology of COPD. In fact, from a risk assessment perspective, the remaining uncertainties, such as definitions of phenotypes, life-time course, and distinction of acute and long-term effects, are less relevant, thus supporting the inclusion of COPD related mortality in the global burden study [35]. However, from an aetiological research perspective, the inconsistencies in the UK studies, the reliance on cross-sectional analyses and the use of different proxies of exposure require some caution in making final judgements. The ambiguity in these studies contrasts with supportive indirect evidence related to biological plausibility. A causal role of air pollution in the induction of COPD would be biologically plausible. Strong redox activity leading to oxidative stress, pulmonary and systemic inflammatory responses, reduction in the ciliary activity in the air ways, amplification of viral infections, increases in bronchial reactivity among predisposed, or acute decrease of pulmonary function are all known effects of acute exposures to several pollutants encountered in ambient air such as particles of various size, ozone, nitrogen dioxide and others [45]. Many of these toxicological features may be relevant in the induction and/or course of COPD. It is also important to note that exposure to products of incomplete combustion from sources that share a range of pollutants in common with ambient air pollution, albeit at higher levels, (i.e. tobacco smoking, certain occupational exposures and indoor biomass combustion) is consistently associated with COPD, though the strength of the evidence varies among the different combustion sources [8]. To elucidate the role of ambient air pollution in the development of COPD, future studies need to elaborate on several issues.

First, better definitions of COPD phenotypes are crucial to overcome current limitations. This includes clinical studies to compare the features of COPD in smokers and nonsmokers. The use of objective measures such as post-bronchodilator lung function measurements and the examination of associations between different phenotypes within COPD are essential. Understanding the role of symptoms in the aetiology of COPD and the relevance of reduced lung function early in life and the rate of lung function decline in adults for the development of COPD will be important for an integrated assessment of the aetiological role of air pollution.

Second, individual assignment of long-term exposure to ambient air pollution remains a relevant task. Measurements and modelling strategies of source specific pollutants will provide results particularly useful for source specific policy making. Exposure during various time windows ought to be considered to elucidate the role of early life exposures and the impact of changes of air quality over time, both indoors and outdoors.

Third, the use or implementation of very large cohort studies will provide the tools to assess the role of susceptibility factors. This is of particular relevance to identify those at highest risk for air pollution-related COPD. To elucidate the role of endogenous and exogenous modifying factors, cohort studies need extensive assessment of objective and subjective covariates, including comorbidities, socioeconomic conditions and deprivation, and access to biobanks (biomarkers and -omics data). Given the partly similar nature of

TABLE 3 Lessons learned from reviewing the air pollution and chronic obstructive pulmonary disease (COPD) evidence and the remaining uncertainties in interpreting this literature

Topic

Limitations in interpretation

Epidemiological evidence

COPD phenotypes

Life-time course of diseases

Role of acute versus long-term effects
In spite of plausible models of biological mechanisms, direct epidemiological evidence of the long-term effects of air pollution on COPD prevalence and incidence remains suggestive but not conclusive

A major obstacle to understanding causality relates to loose and heterogeneous definitions of COPD phenotypes

Air pollution affects the growth and decline of lung function but the link between these processes and the development of COPD is not well investigated

Air pollution causes acute respiratory symptoms and exacerbations of COPD

An accumulation of damage to airways resulting from these acute effects is a plausible basis for any link between air pollution and the development of COPD, but direct evidence is lacking 
ambient urban pollution and tobacco smoke, factors modifying the effects of smoking on COPD may be informative in advancing air pollution research. Promising research on air pollution and health outcomes including COPD is currently under way in the European projects of the $7^{\text {th }}$ Framework program, namely ESCAPE (European Study of Cohorts for Air Pollution Effects; www.escapeproject.org) and TRANSPHORM (Transport related Air Pollution and Health impacts - Integrated Methodologies for Assessing Particulate Matter; www.transphorm.eu). The role of traffic-related air pollution on the development of respiratory disease in adults will be assessed in joint meta-analyses across six existing European cohorts [46].

The use of existing cohorts is an efficient first step to further explore the hypotheses addressed in this review. Challenges discussed above highlight however the limitations of pooling existing cohorts only, given the inherent methodological heterogeneities inevitably encountered across different cohorts. Highly standardised large-scale national, if not international, cohorts will be needed to reveal the role of air pollution (and other factors) in the development and course of chronic diseases such as COPD [47].

In summary, evidence of chronic effects of air pollution on the prevalence and incidence of COPD among adults is suggestive but not conclusive despite plausible biological mechanisms and several high-quality epidemiological studies that support the evidence. To the extent that impaired lung function growth in early life translates into COPD in adulthood, the evidence for a causal link of air pollution with COPD development could be considered substantial [8]. If repeated exacerbations of COPD are considered a cause of the development of the disease, evidence for a causal role of air pollution would again be substantial given the ability of air pollution to trigger exacerbations [48]. However, based on the studies shown in table 1 alone, the role of air pollution in the development of COPD remains uncertain.

\section{Acknowledgements}

We like to thank R. Rapp of the LUDOK air pollution search system at SwissTPH for support (http://ludok.swisstph.ch). We also wish to thank the Secretariat to the Committee on the Medical Effects of Air Pollutants (COMEAP) for use of its systematic literature search on air pollution and COPD as a cross-check in the preparation of this paper. The Secretariat to COMEAP is provided by the UK Health Protection Agency (HPA).

The views expressed in this paper are those of the authors and do not necessarily reflect the views of the Health Effects Institute or its sponsors, or those of the HPA.

\section{References}

1 Kunzli N, Perez L, von Klot S, et al. Investigating air pollution and atherosclerosis in humans: concepts and outlook. Prog Cardiovasc Dis 2011; 53: 334-343.

Decramer M, Janssens W, Miravitlles M. Chronic obstructive pulmonary disease. Lancet 2012; 379: 1341-1351.

Peacock JL, Anderson HR, Bremner SA, et al. Outdoor air pollution and respiratory health in patients with COPD. Thorax 2011; 66: 591-596.

4 Sunyer J. Urban air pollution and chronic obstructive pulmonary disease: a review. Eur Respir J 2001; 17: 1024-1033.

5 Atkinson RW, Anderson HR, Sunyer J, et al. Acute effects of particulate air pollution on respiratory admissions: Results from aphea 2 project. Air pollution and health: a European approach. Am J Respir Crit Care Med 2001; 164: 1860-1866.

6 Künzli N, Perez L, Rapp R. Air quality and health. Lausanne, European Respiratory Society, 2010.

7 World Health Organisation. WHO air quality guidelines for particulate matter, ozone, nitrogen dioxide and sulfur dioxide global update 2005. Geneva, Switzerland, 2006.

8 Eisner MD, Anthonisen N, Coultas D, et al. An official American Thoracic Society public policy statement: novel risk factors and the global burden of chronic obstructive pulmonary disease. Am J Respir Crit Care Med 2010; 182: 693-718.

9 World Health Organisation. The world health report 2008 - primary health care. Geneva, Switzerland, 2008.

10 Health Effects Institute. Traffic-related air pollution: a critical review of the literature on emissions, exposure, and health effects. Boston, Health Effects Institute, 2010.

11 Pujades-Rodriguez M, McKeever T, Lewis S, et al. Effect of traffic pollution on respiratory and allergic disease in adults: cross-sectional and longitudinal analyses. BMC Pulm Med 2009; 9: 42.

12 Schikowski T, Ranft U, Sugiri D, et al. Decline in air pollution and change in prevalence in respiratory symptoms and chronic obstructive pulmonary disease in elderly women. Respir Res 2010; 11: 113.

13 Nuvolone D, Della Maggiore R, Maio S, et al. Geographical information system and environmental epidemiology: a cross-sectional spatial analysis of the effects of traffic-related air pollution on population respiratory health. Environ Health 2011; 10: 12.

14 Andersen ZJ, Hvidberg M, Jensen SS, et al. Chronic obstructive pulmonary disease and long-term exposure to traffic-related air pollution: a cohort study. Am J Respir Crit Care Med 2011; 183: 455-461.

15 Zanobetti A, Bind MA, Schwartz J. Particulate air pollution and survival in a COPD cohort. Environ Health 2008; 7: 48.

16 Yorifuji T, Kashima S, Tsuda T, et al. Long-term exposure to traffic-related air pollution and mortality in Shizuoka, Japan. Occup Environ Med 2010; 67: 111-117.

17 Liu LJ, Curjuric I, Keidel D, et al. Characterization of source-specific air pollution exposure for a large populationbased Swiss cohort (SAPALDIA). Environ Health Perspect 2007; 115: 1638-1645.

18 Kelly FJ, Fussell JC. Air pollution and airway disease. Clin Exp Allergy 2011; 41: 1059-1071.

19 Guder G, Brenner S, Angermann CE, et al. GOLD or lower limit of normal definition? A comparison with expertbased diagnosis of chronic obstructive pulmonary disease in a prospective cohort-study. Respir Res 2012; 13: 13. 
20 Karakatsani A, Andreadaki S, Katsouyanni K, et al. Air pollution in relation to manifestations of chronic pulmonary disease: a nested case-control study in Athens, Greece. Eur J Epidemiol 2003; 18: 45-53.

21 Pujades-Rodriguez M, Lewis S, McKeever T, et al. Effect of living close to a main road on asthma, allergy, lung function and chronic obstructive pulmonary disease. Occup Environ Med 2009; 66: 679-684.

22 Schikowski T, Sugiri D, Ranft U, et al. Long-term air pollution exposure and living close to busy roads are associated with copd in women. Respir Res 2005; 6: 152.

23 Schikowski T, Sugiri D, Reimann V, et al. Contribution of smoking and air pollution exposure in urban areas to social differences in respiratory health. BMC public health 2008; 8: 179.

24 Finkelstein MM, Jerrett M, Sears MR. Traffic air pollution and mortality rate advancement periods. Am J Epidemiol 2004; 160: 173-177.

25 Lepeule J, Laden F, Dockery D, et al. Chronic exposure to fine particles and mortality: an extended follow-up of the harvard six cities study from 1974 to 2009. Environ Health Perspect. 2012; 120: 965-970.

26 Naess O, Nafstad P, Aamodt G, et al. Relation between concentration of air pollution and cause-specific mortality: Four-year exposures to nitrogen dioxide and particulate matter pollutants in 470 neighborhoods in Oslo, Norway. Am J Epidemiol 2007; 165: 435-443.

27 Pope CA 3rd, Burnett RT, Thurston GD, et al. Cardiovascular mortality and long-term exposure to particulate air pollution: epidemiological evidence of general pathophysiological pathways of disease. Circulation 2004; 109: 71-77.

28 Götschi T, Heinrich J, Sunyer J, et al. Long-term effects of ambient air pollution on lung function: a review. Epidemiology 2008; 19: 690-701.

29 Jin LB, Qin Y, Xu Z, et al. [Association between air pollution and mortality in Benxi]. Chin J Public Health 1999; 15: $211-212$

30 Anderson RF, Atkinson GRW. Long-term exposure to air pollution and the incidence of asthma: Meta-analysis of cohort studies. Air Qual Atm Health 2013; 6: 47-56.

31 Jacquemin B, Schikowski T, Carsin AE, et al. The role of air pollution in adult-onset asthma: A review of the current evidence. Sem Respir Crit Care Med 2012; 33: 606-619.

32 Johansson LA, Bjorkenstam C, Westerling R. Unexplained differences between hospital and mortality data indicated mistakes in death certification: an investigation of 1,094 deaths in sweden during 1995. J Clin Epidemiol 2009; 62: 1202-1209.

33 Mannino DM, Brown C, Giovino GA. Obstructive lung disease deaths in the United States from 1979 through 1993. Am J Respir Crit Care Med 1997; 156: 814-818.

34 Hansell AL. Lies, damned lies and mortality statistics? Thorax 2006; 61: 923-924.

35 Lim S, Vos T, Abraham D, et al. The burden of disease and injury attributable to 67 risk factors and risk factor clusters in 21 regions 1990-2010: a systematic analysis. Lancet 2012; 380: 2224-2260.

36 Lipsett MJ, Ostro BD, Reynolds P, et al. Long-term exposure to air pollution and cardiorespiratory disease in the California Teachers Study cohort. Am J Respir Crit Care Med 2011; 184: 828-835.

37 Probst-Hensch NM, Curjuric I, Bridevaux PO, et al. Longitudinal change of pre-bronchodilator spirometric obstruction and health outcomes - results from the SAPALDIA cohort. Thorax 2010; 65: 150-156.

38 Seemungal T, Harper-Owen R, Bhowmik A, et al. Respiratory viruses, symptoms, and inflammatory markers in acute exacerbations and stable chronic obstructive pulmonary disease. Am J Respir Crit Care Med 2001; 164: $1618-1623$.

39 Seemungal TA, Harper-Owen R, Bhowmik A, et al. Detection of rhinovirus in induced sputum at exacerbation of chronic obstructive pulmonary disease. Eur Respir J 2000; 16: 677-683.

40 Lotvall J, Akdis CA, Bacharier LB, et al. Asthma endotypes: A new approach to classification of disease entities within the asthma syndrome. J Allergy Clin Immunol 2011; 127: 355-360.

41 Marsh SE, Travers J, Weatherall M, et al. Proportional classifications of COPD phenotypes. Thorax 2008; 63: 761-767.

42 Weatherall M, Travers J, Shirtcliffe PM, et al. Distinct clinical phenotypes of airways disease defined by cluster analysis. Eur Respir J 2009; 34: 812-818.

43 Guerra S. Asthma and chronic obstructive pulmonary disease. Curr Opin Allergy Clin Immunol 2009; 9: 409-416.

44 Gauderman WJ, Avol E, Gilliland F, et al. The effect of air pollution on lung development from 10 to 18 years of age. N Engl J Med 2004; 351: 1057-1067.

45 Donaldson GC, Seemungal TA, Bhowmik A, et al. Relationship between exacerbation frequency and lung function decline in chronic obstructive pulmonary disease. Thorax 2002; 57: 847-852.

46 Eeftens M, Beelen R, de Hoogh K, et al. Development of land use regression models for PM2.5, PM2.5 absorbance, PM10 and PMcoarse in 20 European study areas; results of the ESCAPE project. Environ Sci Technol 2012; 46: 11195-11205.

47 Probst-Hensch NM. Chronic age-related diseases share risk factors: do they share pathophysiological mechanisms and why does that matter? Swiss Med Wkly 2010; 140: w13072.

48 Wedzicha JA, Seemungal TA. COPD exacerbations: defining their cause and prevention. Lancet 2007; 370: 786-796. 